\title{
IMPROVING THE EFFICIENCY OF HYBRID WELDING OF ALUMINUM ALLOYS*
}

\author{
V.Yu. KHASKIN ${ }^{2}$, V.N. KORZIK ${ }^{1,2}$, V.N. SYDORETS ${ }^{2}$, \\ A.I. BUSHMA ${ }^{2}$, WU BOYI ${ }^{1}$ and LUO ZIYI ${ }^{1}$ \\ ${ }^{1}$ Chinese-Ukrainian E.O. Paton Welding Institute (Guangdong General Research Institute of Industrial Technology) \\ (Guangzhou Research Institute of Non-Ferrous Metals) \\ 363 Changxing Road, Tianhe, 510650, Guangzhou, China. E-mail: vnkorzhyk@gmail.com \\ ${ }^{2}$ E.O. Paton Electric Welding Institute, NASU \\ 11 Bozhenko Str., 03680, Kiev, Ukraine. E-mail: office@paton.kiev.ua
}

\begin{abstract}
Development of new laser-arc heat sources is one of the urgent directions of modern science and engineering in the field of fusion welding of metals. Allowing for their physical features can promote increase of laser-arc welding productivity due to improvement of effective efficiency, i.e. increase of the ratio of power of the heat source applied to the metal in welding to the total power of the electric arc and laser radiation. One of the ways to improve the effective efficiency of welding is reduction of laser energy losses associated with radiation reflection from the surface being welded. The work is a study of the influence of concurrent heating, provided by the electric arc, on the change of the conditions of laser radiation absorption by aluminum alloys in their laser-arc welding. The problem of determination of temperature dependence of the coefficient of laser radiation absorption by aluminum was defined and solved within the model of almost free electrons on the base of studying vapour-gas channel behavior in hybrid welding. Comparison of obtained calculation dependencies of absorption capacity with the available experimental data showed satisfactory agreement. The respective heat conductivity equation was solved, in order to determine such parameters of laser-arc welding mode as arc component power and distance between the arc impact zone and laser beam axis. Experimental verification of the proposed approach to increase of effective efficiency of laser welding, performed on samples of aluminum alloy AMg6, confirmed the validity of the predicted results. 12 Ref., 7 Figures.
\end{abstract}

Keywords: laser-arc welding, aluminum alloys, $\mathrm{CO}_{2}$-laser radiation, absorption coefficient, welding current, welding speed

One of the urgent problems of modern science and technology in the field of fusion welding of metals is to create new heat sources, which allow control the concentration of heat energy inputted into the metal during welding. This finally makes it possible to ensure the required welding performance, quality of the welded joint, process stability and reproducibility of its results. The hybrid laser-arc source is increasingly used in recent years as such controlled heat source for welding of metal materials, which is implemented by jointly thermal effects on the metal being welded (within the total heating zone) by focused laser beam and electric arc [1].

In addition, the patterns of mutual effects of the components of laser-arc heat source and their joint effect on various metal materials are not studied enough.
The study of physics of the processes of interaction of components of the laser-arc heat energy source between themselves and their combined effect on the welded metal, the development of appropriate mathematical models and computer simulations of these processes are highly relevant scientific and technical problems. These tasks include consideration of physical characteristics of the hybrid laser-arc welding of aluminum alloys, which allows increasing its performance by increasing the effective efficiency, i.e. increasing the ratio of power of the heat source, acting in the metal during welding, to the total power of the electric arc and laser radiation. One of the ways to improve the efficiency of welding is reduction of laser energy losses associated with the reflection of radiation from the surface being welded.

Therefore, the objective of this work is to study the influence of concurrent heating, ensured by electric arc, on changing the conditions of absorption of laser radiation by aluminum alloys in their laser-arc welding, as well as the

\footnotetext{
* This work was support by the Financial Funding by Foreign Experts Program of China (No. WQ20124400119) by Innovative R\&D Team of Guangdong Province (No. 201101C0104901263) and by China International science and technology cooperation special items «Research on High Efficient Welding Equipment and Key Technology for Special Ships of Aluminum Alloy» (No. 2013DFR70160).
} 
definition of welding parameters, ensuring increasing the effective efficiency by reducing losses of laser energy.

Laser-arc welding, as well as laser welding, is characterized by the formation of vapor-gas channel of penetration in the welded metal. Paper [2] describes in detail the behavior of this channel during welding. In particular, it was noted that in its front wall there is a layer of molten metal, which is under constant «indignation» as the formation of step-like curvature, which periodically moves along the height of the channel. At this, the removal of material from the front wall is carried out layer by layer while moving downward step. This can be explained by increasing of the molten metal layer at the front wall, occurring due to transfer of radiation energy into the heat energy emitted at this wall, in combination with the hydrodynamic processes in the weld pool.

It is known that the part of radiation energy is absorbed by the welded metal, and another part is reflected from it. The proportion of the absorbed radiation greater, the higher is the temperature of the metal. Melt formed on the front wall absorbs radiation, but at the account of moving along the direction of welding the front part of the laser beam always contact the slightly heated metal, that leads to lowering of absorption coefficient.

It is logical to assume that the local heating up to certain temperatures of a small site of the welded metal, located directly in front of vapor-gas channel along the direction of welding, can significantly increase the rate of absorption of laser radiation. In the case of laser-arc welding, performed under the scheme provided in Figure 1, such local heating is carried out by electric arc. There is a task of achieving minimum temperatures sufficient for maximum possible increasing the radiation absorption coefficient, depending on welding speed and welded item geometry.

To determine the temperature dependence of the coefficient of absorption of laser radiation by metal materials $A\left(T_{s}\right)$ we will consider the studied metal (aluminum) in framework of model of almost free electrons. In this case, according to the formulas of Drude-Zener [3], for the actual $\varepsilon_{1}$ and imaginary $\varepsilon_{2}$ parts of the complex dielectric permeability of the metal on the frequency of laser radiation $\omega=2 \pi c / \lambda$ (where $c-$ light velocity, and $\lambda-$ wavelength of radiation), we get:

$$
\begin{gathered}
\varepsilon_{1}=1-\frac{\omega_{\mathrm{p}}^{2}}{\omega^{2}+\omega_{\mathrm{c}}^{2}}, \\
\varepsilon_{2} \omega=4 \pi \sigma=\frac{\omega_{\mathrm{c}} \omega_{\mathrm{p}}^{2}}{\omega^{2}+\omega_{\mathrm{c}}^{2}} .
\end{gathered}
$$

Here $\omega_{\mathrm{p}}$ is the frequency of the plasma oscillations of metal free electrons; $\omega_{c}$ is the frequency

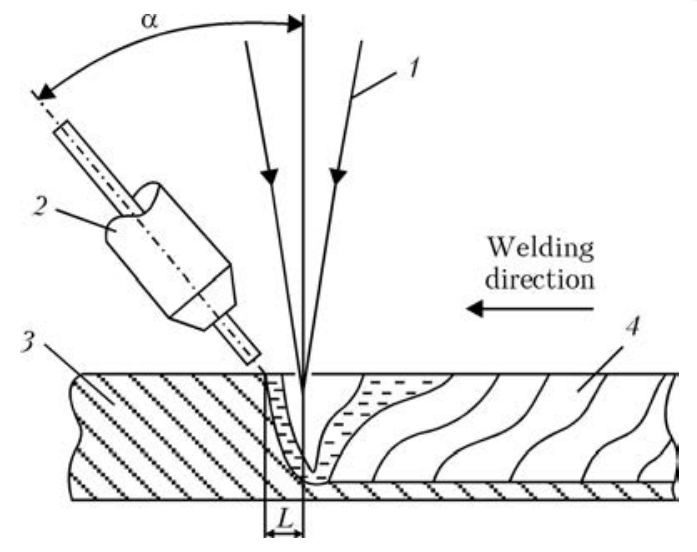

Figure 1. Scheme of hybrid laser-arc welding: 1 - focused laser radiation; 2 - consumable-electrode arc; 3 - specimen; 4 - welded joint; $L$ - distance between electrode wire and laser axis

numerically equal to the reverse time of relaxation time of the conduction electrons.

The value of the plasma frequency is determined by formula

$$
\omega_{\mathrm{p}}^{2}=\frac{4 \pi n e N_{\mathrm{e}}}{m_{\mathrm{e}}^{*}},
$$

where $e$ and $m_{\mathrm{e}}^{*}$ is the charge and effective mass of electron in the metal [4]. Concentration of the conduction electrons $N_{\mathrm{e}}=V / \Omega$ is determined by valence $V$ and atom volume $\Omega$. Valence for aluminum was assumed to be 3 . Atom volume was obtained on the basis of experimental data on density of aluminum provided in [5].

In the limiting case of constant field when $\omega$ $=0$, the high optical conductivity $\sigma$ turns into static conductivity of the metal:

$$
\sigma(0)=\frac{N_{\mathrm{e}} e}{m_{\mathrm{e}} \omega_{\mathrm{c}}} .
$$

The temperature dependence of the relaxation frequency $\omega_{\mathrm{c}}$ for the considered metals in solid state was taken into account using the following formula [6]:

$$
\omega_{\mathrm{c}}=K^{\prime} T^{5} \int_{0}^{\theta / I} \frac{z^{4} d z}{e^{z}-1},
$$

where $\theta$ is the Debye temperature; $K^{\prime}$ is the constant. Values $\omega_{c}$ and, consequently, $K^{\prime}$ at room temperature for aluminum were chosen in accordance with data of [7]. For aluminum in liquid state the experimental values from [8,9] were used. The design data obtained using this way are shown in Figure 2.

The temperature dependence presented has distinctive gap at melting point of the metal $T_{\mathrm{m}}$. According formulas (1) and (2) with use of (3)-(5) the temperature dependences of actual and imaginary parts of the complex dielectric permeability for aluminum at radiation frequency of $\mathrm{CO}_{2}$-laser $(\lambda=1.06 \mu \mathrm{m})$ were developed (Figure 3$)$.

For further calculations, it is convenient to introduce the actual $n$ and imaginary $k$ parts of 


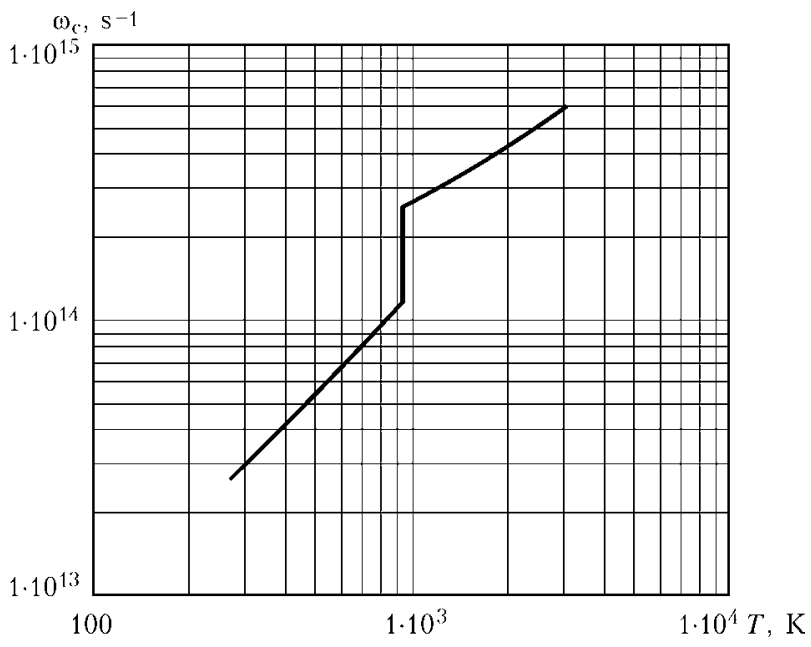

Figure 2. Relaxation frequency $\omega_{\mathrm{c}}$ versus temperature $T$ for aluminum at influence of $\mathrm{CO}_{2}$-laser radiation on it $(\lambda=$ $=10.6 \mu \mathrm{m}$ )

complex refraction index of the metal at frequency of the laser radiation:

$$
\sqrt{\varepsilon}=\sqrt{\varepsilon_{1} i \varepsilon_{2}}=n+i k
$$

using the following formulas:

$$
\begin{aligned}
& n=\frac{\sqrt{\sqrt{\varepsilon_{1}^{2}+\varepsilon_{2}^{2}+\varepsilon_{1}}}}{2}, \\
& k=\frac{\sqrt{\sqrt{\varepsilon_{1}^{2}+\varepsilon_{2}^{2}-\varepsilon_{1}}}}{2} .
\end{aligned}
$$

The temperature dependence of actual and imaginary parts of the complex refraction index for aluminum are shown in Figure 4.

Using obtained $n$ and $k$ values, we determine the absorption coefficient of laser radiation normally incident on a flat surface of metal (absorbability), using the well-known formula

$$
A=\frac{4 n}{(1+n)^{2}+k^{2}} \text {. }
$$

In some cases, a more important parameter is coefficient of reflection (reflectivity), which can be defined by formula

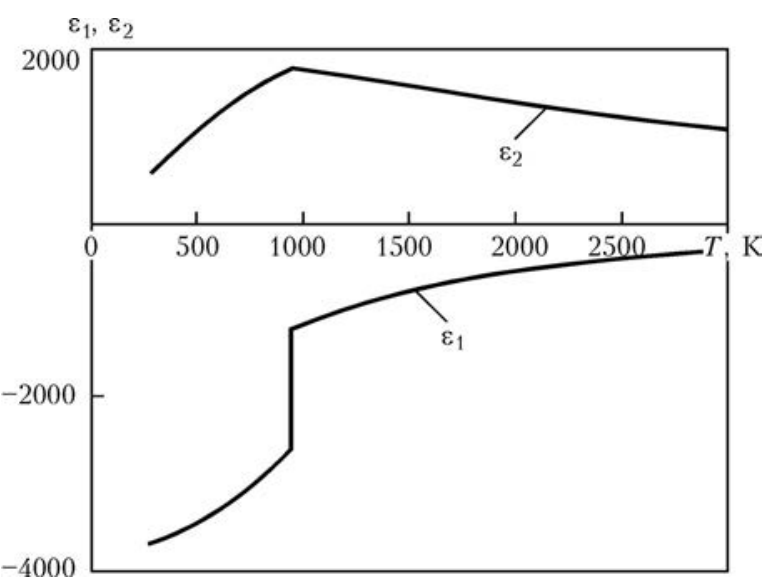

Figure 3. Temperature dependence of actual $\varepsilon_{1}$ and imaginary $\varepsilon_{2}$ parts of complex dielectric permeability of aluminum

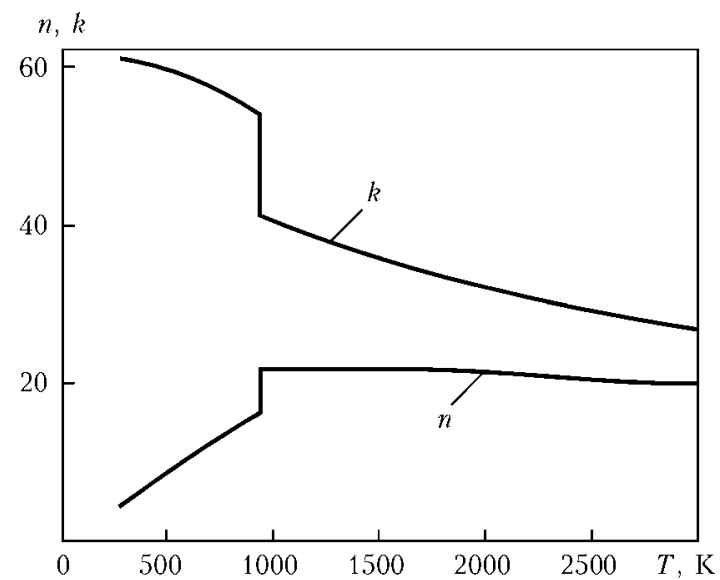

Figure 4. Dependence of actual $n$ and imaginary $k$ parts of complex refraction index of aluminum on temperature

$$
R=1-A=\frac{(1-n)^{2}+k^{2}}{(1+n)^{2}+k^{2}} .
$$

Figure $5, a$ shows the results of calculations of the temperature dependences of coefficient of $\mathrm{CO}_{2}$-laser radiation absorption for aluminum in the temperatures range from room to boiling ones and above. Similar calculations were conducted for determining the absorbability of aluminum surface in the case of falling of radiation of Nd:YAG-laser $(\lambda=1.06 \mu \mathrm{m})$ on it. They showed identical behavior of both dependences with the difference that the absolute values of the radiation absorption coefficient of Nd:YAG-laser is higher than that of $\mathrm{CO}_{2}$-laser (Figure $5, b$ ).

Estimated dependences of absorbability obtained for both types of radiation was compared with the available experimental data [6-9], and the match was quite satisfactory. According to the dependences, shown in Figure 5, to achieve the maximum values of absorption coefficient the surface of aluminum alloy being welded in the zone of action of laser radiation of both wavelengths should be heated up to melting temperature $T_{\mathrm{m}}$. However, even heating up to $T_{\mathrm{m}}$ is sufficient to dramatically abrupt increase the absorbability.

To determine such parameters of laser-arc welding mode as power $Q_{\mathrm{a}}$ of arc component and distance $L$ between the point of feeding the electrode wire and the axis of laser radiation (see Figure 1), it is necessary to solve the corresponding equation of heat conductivity. To simplify the task, we will consider the stationary case of heating of aluminum plate of thickness $\delta$ by arc source, the heat flow of which is determined by dependence

$$
Q_{\mathrm{a}}=\eta I U,
$$

where $\eta$ is the efficiency of consumable-electrode arc usually taken as $0.8 ; I$ is the welding current, A; $U$ is the arc voltage, $\mathrm{V}$.

Let us assume that the spatial distribution of heat flow inputted into the sample symmetrically 
with axis, perpendicular to its surface (i.e. symmetrically with laser beam axis).

In this regard, we formulate a mathematical model of heating of considered sample in axially symmetric statement. Equation of heat conductivity in a metal can be written in the cylindrical coordinate system taking into account the axial symmetry of the temperature field:

$$
\begin{gathered}
C_{\mathrm{m}}(T) \rho_{\mathrm{m}}(T) \frac{\partial T}{\partial t}=\frac{1}{r} \frac{\partial}{\partial r}\left(r \lambda_{\mathrm{m}}(T) \frac{\partial T}{\partial r}\right)+ \\
+\frac{\partial}{\partial z}\left(\lambda_{\mathrm{m}}(T) \frac{\partial T}{\partial z}\right),
\end{gathered}
$$

where $C_{\mathrm{m}}(T), \rho_{\mathrm{m}}(T), \lambda_{\mathrm{m}}(T)$ is the effective heat capacity of metal (taking into account the melting latent heat), the density and thermal conductivity coefficient, respectively, wherein the $r$-axis is directed along the sample surface, and the $z$-axis is directed into the sample, perpendicular to its surface.

Boundary equation (12) we put in the range $0 \leq r \leq R, 0 \leq z \leq \delta, t \geq 0$ (where $R$ - radius of the computational region, and $\delta$ - sample thickness). As the initial conditions in the entire region the temperature $T_{0}$ is given, which is equal to the ambient temperature. At $r=0$ we put the condition of temperature field symmetry

$$
\frac{\partial T}{\partial r_{r=0}}=0 .
$$

It is expected that at characteristic time, during which it is necessary to find a solution of the problem, the thermal perturbation does not reach the outer limits of the computational region, i.e. at these limits the initial temperature is

$$
T(r, \delta, t)=T(R, z, t)=T_{0} .
$$

On the sample surface affected by the pulsed heat source we put the following boundary condition:

$$
-\lambda_{\mathrm{m}}(T) \frac{\partial T}{\partial z_{z=0}}=Q_{\mathrm{a}} .
$$

Here $Q_{\mathrm{a}}(r, t)$ is the space-time distribution of the heat flow introduced into the metal by pulsed arc discharge, determined according to dependences (11) on the average value of welding current.

Maximum temperature $T_{\mathrm{c}}$ in the arc center of supply power $Q_{\mathrm{a}}$ was determined by the Newton-Richmann law (where $Q_{\mathrm{a}}=\alpha\left(T_{\mathrm{c}}-T_{0}\right)-$ heat transfer coefficient $\left[\mathrm{W} /\left(\mathrm{m}^{2} \cdot \mathrm{K}\right)\right]$ found experimentally for aluminum alloy $\operatorname{AMg} 6(1 / \alpha=$ $=0.55-0.60)$ ).

The solution of problem (12)-(15) was found numerically by the Peasmen-Rachford method [10] for aluminum plate $2 \mathrm{~mm}$ thick. In carrying out of all calculations thermal characteristics of aluminum alloy $\mathrm{AMg} 6$ given in [11] have been used.
A, \%
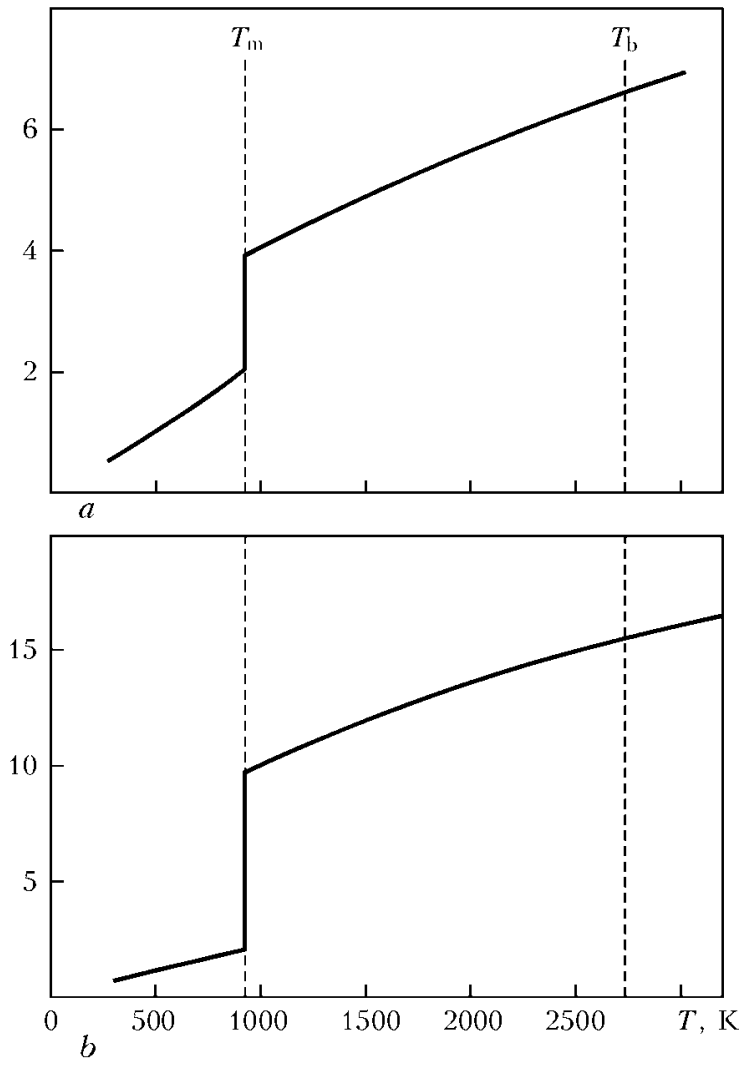

Figure 5. Absorption capacity $A$ versus temperature $T$ for aluminum at wavelength of $10.6(a)$ and $1.06(b) \mu \mathrm{m}$

We calculated the temperature distribution created by arc source power $Q_{\mathrm{a}}$ on the surface of aluminum plate along the $x$-axis in direction opposite the direction of welding. Welding speed $v_{\mathrm{w}}$ we considered in determining the exposure time of arc source, calculated by dependence $\tau=d / v_{\mathrm{w}}$ (where $d-$ size of heat source on the surface of plate being welded (we took $d=2 \mathrm{~mm}$ )).

Calculations for three cases of welding were carried out: with average technological parameters $Q_{\mathrm{a}} \approx 3.1 \mathrm{~kW}, I \approx 150 \mathrm{~A}, v_{\mathrm{w}}=130 \mathrm{~m} / \mathrm{h}$; at economy mode with relatively low speed and power $\left(Q_{\mathrm{a}} \approx 2.1 \mathrm{~kW}, I \approx 100 \mathrm{~A}, v_{\mathrm{w}}=120 \mathrm{~m} / \mathrm{h}\right)$; and with high performance $\left(Q_{\mathrm{a}} \approx 4.1 \mathrm{~kW}, I \approx\right.$ $\left.\approx 200 \mathrm{~A}, v_{\mathrm{w}}=300 \mathrm{~m} / \mathrm{h}\right)$. For these cases we determined the distribution of temperatures along the $x$-axis from the center of action of the arc power source (Figure 6).

Results of calculations have showed that in case of welding with average process parameters, distance $L$ (see Figure 1) should not exceed $2 \mathrm{~mm}$. During welding at economy mode, $L$ should be in the range up to $0.8 \mathrm{~mm}$, and during high-performance welding - up to $1.5 \mathrm{~mm}$. The excess of calculated distance will reduce the absorption capacity $A(T)$, increase the proportion of losses of laser radiation due to its reflection from the surface of aluminum alloy and, consequently, reduce the productivity. It should be noted that further increase of hybrid welding 


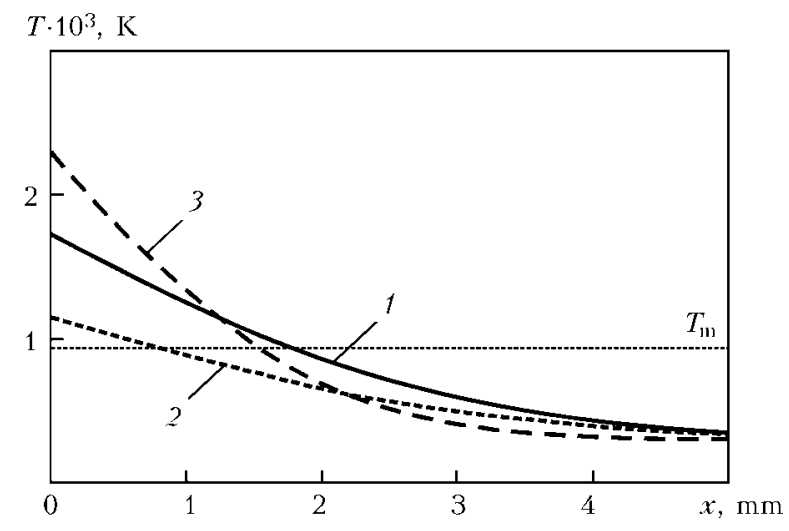

Figure 6. Temperature distribution on the surface of aluminum plate $2 \mathrm{~mm}$ thick from the arc source in welding direction $x: 1-I=150 \mathrm{~A}, v_{\mathrm{w}}=130 \mathrm{~m} / \mathrm{h} ; 2-I=100 \mathrm{~A}$, $v_{\mathrm{w}}=120 \mathrm{~m} / \mathrm{h} ; 3-I=200 \mathrm{~A}, v_{\mathrm{w}}=300 \mathrm{~m} / \mathrm{h}$

performance leads to the need in distance $L$ reduce. This, on reaching certain mode parameters, may lead to deterioration of absorption capacity and getting the lacks-of-fusion because of problematic of ensuring condition $L<1 \mathrm{~mm}$.

Experimental verification of the predicted approach to improve the effective efficiency of hybrid welding due to selection of distance $L$ between the point of wire supply and the laser axis was conducted on samples of aluminum alloy AMg6 with $\delta=2 \mathrm{~mm}$ using welding wire SvAMg6 of $1.2 \mathrm{~mm}$ diameter. At this, we used up to $10 \mathrm{~kW} \mathrm{CO}$-laser LT-104 [12] and standard equipment Fronius TPS-2700 for GMAW. Hybrid welding was performed in argon with $8^{-}$ $101 / \mathrm{min}$ consumption for root weld, and 12$14 \mathrm{l} / \mathrm{min}$ for weld pool shielding. At this, power of radiation incident on the sample was $2.5 \mathrm{~kW}$, welding current was varied in the range 60$300 \mathrm{~A}$, and distance $L$ was $1-2 \mathrm{~mm}$ (in average $1.5 \mathrm{~mm}$ ). Electric arc was placed first during the welding direction, and then focused laser beam was used. During the experiments, increasing current $I$, welding speed was determined by the criteria of formation of high-quality welded joint. In the result, the dependence, shown in Figure 7, was obtained.

The analysis of the nature of this dependence suggests the following. As long as power of the arc heat source acting on the surface of aluminum alloy being welded was not enough to create the molten pool on it, the length of which along the $x$-axis would exceed $L$ value, welding performance is almost did not increased with increasing of welding current.

At this, the substantial portion of the laser power was lost due to reflection from the alloy surface. Once the power of heat source was sufficient to create the desired length of the molten pool, there was a sharp increase in welding performance, determined by its speed. In our opinion, it is determined by an abrupt increasing of

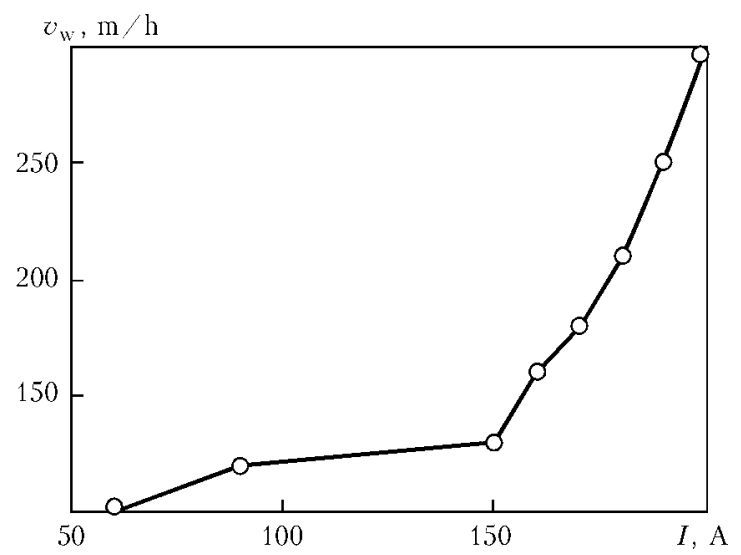

Figure 7. Welding speed versus arc current for laser-arc welding of alloy AMg6 with $\delta=2 \mathrm{~mm}$ at $2.5 \mathrm{~kW}$ power of $\mathrm{CO}_{2}$-laser radiation

absorption capacity and, consequently, improving of effective welding efficiency due to reducing the laser energy losses.

Thus, during hybrid laser-arc welding of aluminum alloys to improve the effective efficiency of the process, the electric arc should provide such concurrent heating, which will allow creating a molten pool, covering the zone of action of focused laser radiation. At this, the share of absorbed laser radiation abruptly increases at least twice for $\mathrm{CO}_{2}-$ laser wavelength, and about 3 times for Nd:YAGlaser wavelength, that has a positive effect not only for total energy contribution, but also for stabilization of the electric arc.

1. Shelyagin, V.D., Khaskin, V.Yu. (2002) Tendencies in development of laser-arc welding (Review). The Paton Welding J., 6, 25-28.

2. Grigoriants, A.G. (1988) Laser equipment and technology: Refer Book. Vol. 5: Laser welding of metals. Moscow: Vysshaya Shkola.

3. Noskov, M.M. (1983) Optical and magneto-optical properties of metals. Sverdlovsk: UNTs AN SSSR.

4. Kiselev, A.I., Akashev, L.A., Kononenko, V.I. (2004) Effective mass of electrons in the alloys of aluminum, cesium and binary system $\mathrm{Al}-3$ at.\% Ce. Zhurnal Tekhnich. Fiziki, 74(3), 20-23.

5. Zinoviev, V.E. (1989) Thermal properties of metals at high temperatures: Refer. Book. Moscow: Metallurgiya.

6. Ujihara, K. (1972) Reflectivity of metals at high temperatures. J. Appl. Physics, 43(5), 2376-2383.

7. Ordal, M.A., Long, L.L., Bell, R.J. et al. (1983) Optical properties of the metals $\mathrm{Al}, \mathrm{Co}, \mathrm{Cu}, \mathrm{Au}, \mathrm{Fe}$, $\mathrm{Pb}, \mathrm{Ni}, \mathrm{Pd}, \mathrm{Pt}, \mathrm{Ag}, \mathrm{Ti}$, and $\mathrm{W}$ in the infrared and far infrared. Appl. Optics, 22(7), 1099-1119.

8. Miller, J.C. (1969) Optical properties of liquid metals at high temperatures. Phil. Magazine, Issue 168, 20(12), 1115-1132

9. Comins, N.R. (1972) The optical properties of liquid metals. Ibid., Issue 4, 25, 817-831.

10. Peacemen, D.W., Rachford, H.H. (1955) The numerical solution of parabolic and elliptic differential equations. J. Soc. Ind. Appl. Math., 3, 28-41.

11. Beletsky, V.M., Krivov, G.A. (2005) Aluminum alloys (composition, properties, technology, application): Refer. Book. Kiev: Komintekh.

12. Garashchuk, V.P., Shelyagin, V.D., Nazarenko, O.K. et al. (1997) Technological CO2-laser LT104 of $10 \mathrm{~kW}$ power. Avtomatich. Svarka, 1, 36-39.

Received 30.09.2015 